\title{
Design and arrangement technology of artificial habitat using old vessel
}

\author{
HYEON-JU KIM $^{1}$ AND CHAN-KYU YANG ${ }^{2}$
}

\begin{abstract}
1Ocean Development System Laboratory, Korea Research Institute of Ships and Ocean Engineering, KORDI, P.O.Box 23, Yusung, Taejon, 305-600, Korea (hjkim@kriso.re.kr) and²(ckyang@kriso.re.kr)
\end{abstract}

SUMMARY: To recycle old fishing vessel as an artificial habitat, design technology is established through physical experiment and numerical simulation. Numerical simulation based on finite volume method with standard $\kappa-\varepsilon$ model and hydraulic experiment using flow visualization scheme are applied to determine sheltered area and reasonable interval between vessel habitats. Reattachment length, as an index of the area, is ranged from 5 to 10 times of vessel height according to Reynolds number. It is necessary of the interval more than 4 times of the length to maximize total area. As results of hydrodynamic experiment, drag coefficient from 1.5 to 2.0 and lift coefficient from 0.3 to 0.8 according to Reynolds number in current field, inertia coefficient of 0.5 in wave field can be applied to estimate demanded weight. Additional measures to enhance fish aggregation are discussed on opening holes with regard to ecological habit of target fish as well as attaching membranes on the hull.

\section{KEY WORDS: artificial habitat, sunken vessel, design, arrangement, numerical simulation, model test}

\section{INTRODUCTION}

To create fishing grounds for sustainable utilization of fisheries resource, artificial habitat technology have been applied in more than 50 nations. Traditional artificial habitats were cube, cylinder, turtle block and so on, which are almost made of reinforced concrete ${ }^{1)}$. Recycling materials such as tire, wooden boat, car etc. have been rarely tried to practice as artificial habitat.

Recently, fishing vessel is under forced to reduce to regulate fishing industrial structure for managing reasonable amount of fishes. About 683 fishing boats had been reduced in Korea, they were abolished or were reused as public ships of no concerned with capture fisheriese. To recycle these used fishing vessel resources, Korean govemment tried to apply as artificial habitat for commercial or sports fishing ${ }^{2)}$.

Though some trials were found in Korea, Japan and USA, they were still remained empirical skill. To expand reuse of old fishing vessel as gravitational type artificial habitat, design and arrangement technology have to be established systematically.

This study aims to establish design and arrangement procedure, and classfy required techniques in the viewpoint of ocean engineering ${ }^{3)}$. Demanded techniques are studied by numerical simulation and physical experiment for practical use.

\section{DESIGN AND ARRANGEMENT PROCEDURES}

The fundamental planning flow for fishing ground creation and innovation were proposed by $\mathrm{Ryu}^{\text {l) }}$ modifying the Japanese guide line. Practical design and arrangement procedures for sunken vessel habitats are assumed as following steps based on the study.

(1) Surveying and analyzing ocean environmental data, desirable fish species and available old vessels as design condition.

(2) Determining manufacture method in consideration with ecological condition of target fishes, which include discarding part and materials, prediction of wake area and stability of installed sunken vessel.

(3) Planning arrangement of distance between the habitats, and additional enforcement of function to maximize effective zone.

(4) Complementing ballast works after stability analysis with towing manufactured vessel 
habitat.

(5) Installing the habitat to exact place with regard to falling behavior and landing impact.

(6) Evaluating environmental conditions, fish abundance and allowable catches due to habitat construction.

To establish above-mentioned procedure, demanded unit technology should be evaluated as a systematic feed-back system in consideration of environmental conditions of the area and change of desirable fish abundance and catches due to the reef construction.

\section{EXPERIMENT AND ANALYSIS METHODS}

Numerical analysis and physical experiment were examined to establish sunken vessel habitat technology. Experiment is tried to investigate physical environment control if there exit the sunken vessel habitat in the current and wave attack.

When the sunken vessel habitat is placed in the uniform flow, there would be vortex behind the habitat that is caused by separation of fluid particles. This makes recirculating flow and free shear layer which are so small velocity compared with far field shown in Fig. 1. Because this phenomena is believed that aggregate more fish, we deals with index of effectiveness of habitat.

Numerical simulations of the two dimensional steady flow around sunken vessel habitat are carried out by the CFD code ${ }^{4)}$ which is developed by using Finite Volume Method and which includes the standard k-e model with standard wall function.

Physical experiments are carried out in circulating tank (30 $\mathrm{mlx} 0.6 \mathrm{mx} 0.8 \mathrm{~m})$ with wave generation. Laser sheet probe to make $2 \mathrm{~mm}$ thick laser sheet are installed as in Fig. 2. After injecting polymer as particle to visualize flow, digital image was captured by image board DT3155 series. Velocity distributions are evaluated by auto-correlation method $^{\text {5) }}$. Fluid forces are measured by $2 \mathrm{D}$ load cell, and falling behavior is observed in the tank..

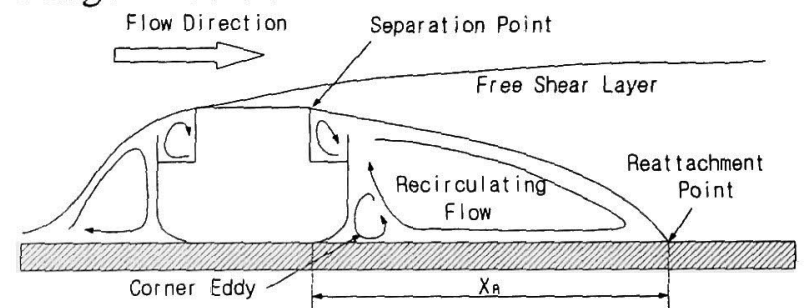

Fig. 1 A flow pattern around the mid-ship section

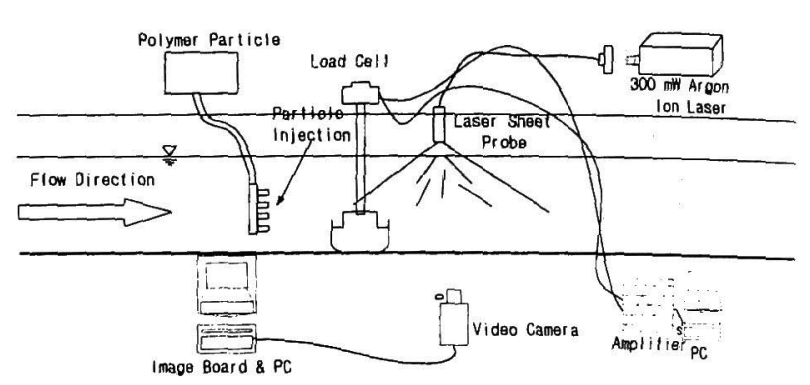

Fig. 2 Experimental apparatus for physical experiment

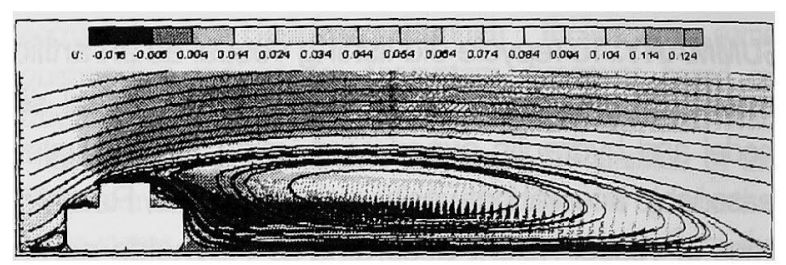

(a) $\mathrm{Rn}=7845$

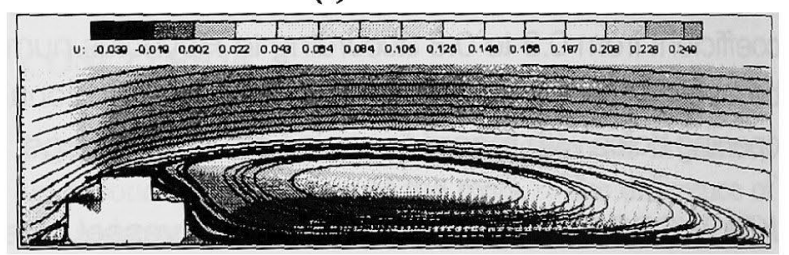

(b) $\mathrm{Rn}=15765$

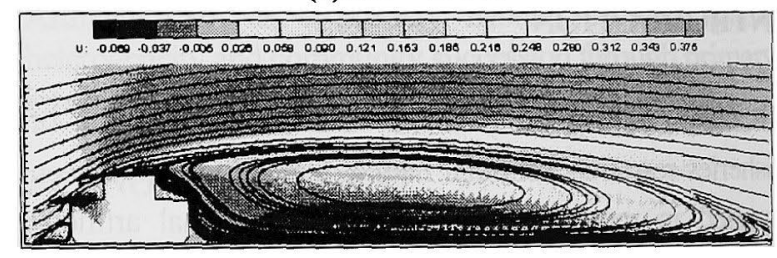

(c) $\mathrm{Rn}=23684$

Fig. 3 Computational results of velocity distributions and streamline pattems

\section{CHARACTERISTIS OF FLOW AROUND HABITAT}

Numerically simulated flow using 2 dimensional CFD code around a sunken vessel habitat is shown in Fig. 3. PIV results by 3 dimensional hydraulic model test is presented in Fig. 4 to compared with. Numerical ones.

Reattachment length as an index of effective habitat area is investigated by the variation of Reynolds number $(\mathrm{Rn})$ shown as Fig. 5. From this figure, the length by $2 \mathrm{D}$ numerical analysis is inclined to about 9.5 times of vessel height with increase of $\mathrm{Rn}$, but length by $3 \mathrm{D}$ physical analysis is reduced to 5.5 times of vessel height. It is anticipated that reattachment length of real vessel will reach 6 or 7 times of vessel height. 


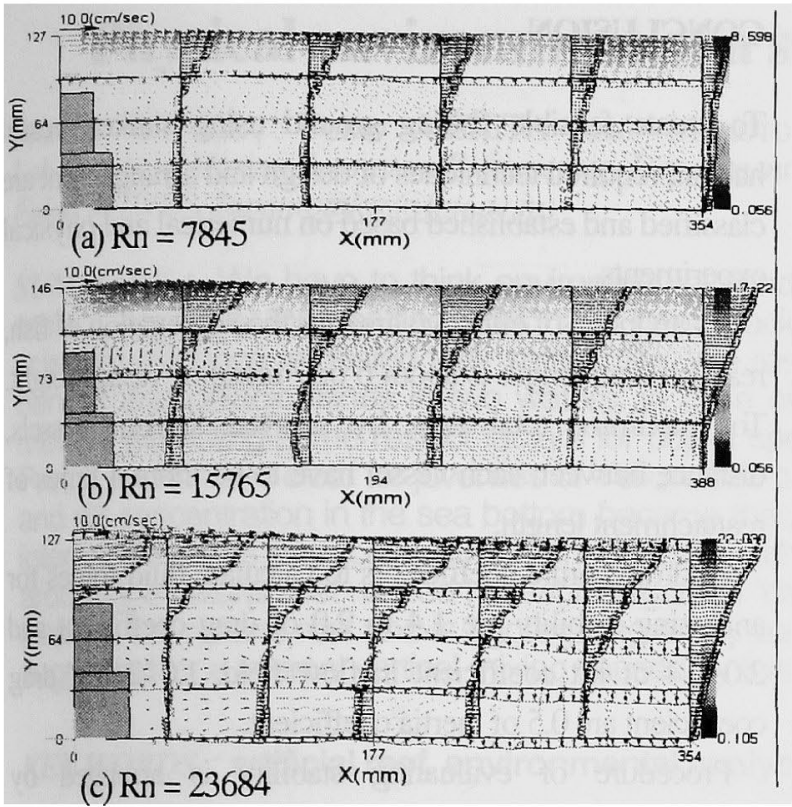

Fig. 4 Exemplified time averaged velocity.

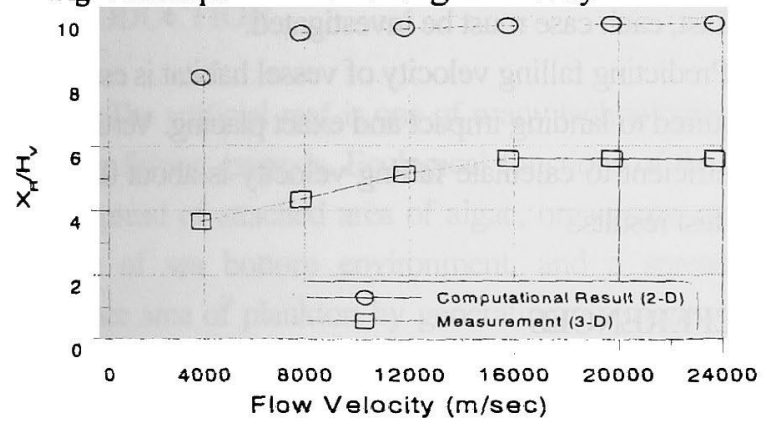

Fig. 5 A comparison of the reattachment length.

To investigate optimal arrangement of vessel habitat array, flow pattern was analyzed by numerical and physical methods shown as Figs. 6 and 7. These results shows total area of two vessels is less than sum of individual ones. To maximize total area by two vessels, behind vessel must be placed at 4 times of reattachment length far from front one according to Shoda's experiment ${ }^{(5)}$.

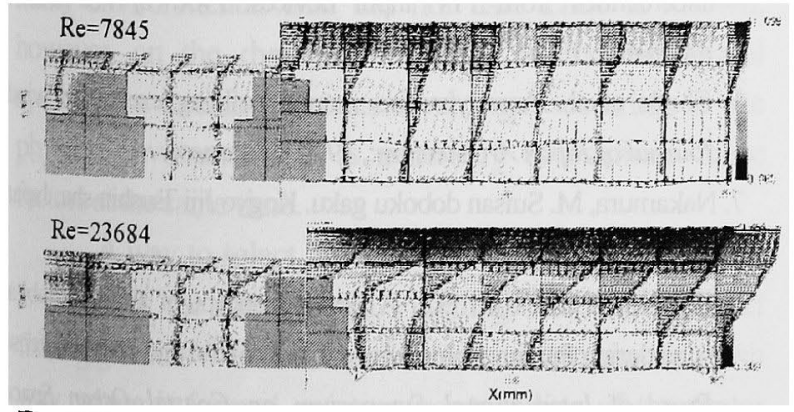

Fig. 6 PIV results around two sunken vessels.

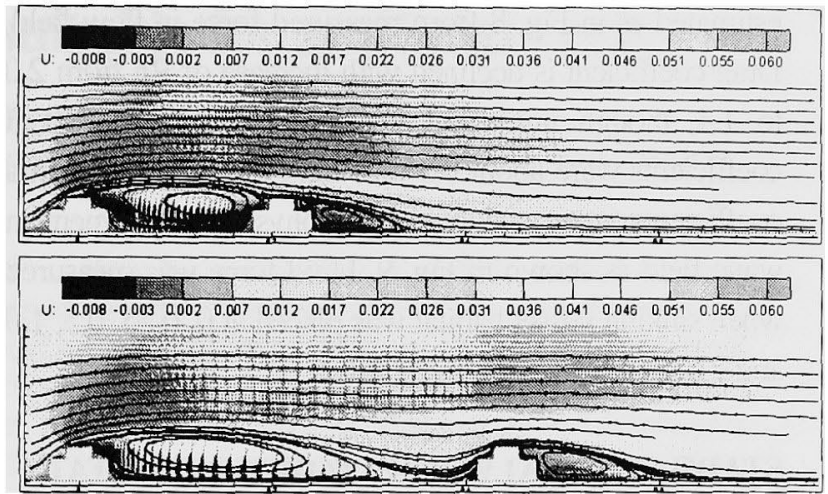

Fig. 7 Computational results for two vessel habitats.

\section{HYDRODYNAMIC CHARACTERISTICS}

Drag force can be calculated by integral of pressure distribution along surface of mid-ship section by $2 \mathrm{D}$ numerical simulation. Drag and lift coefficients were

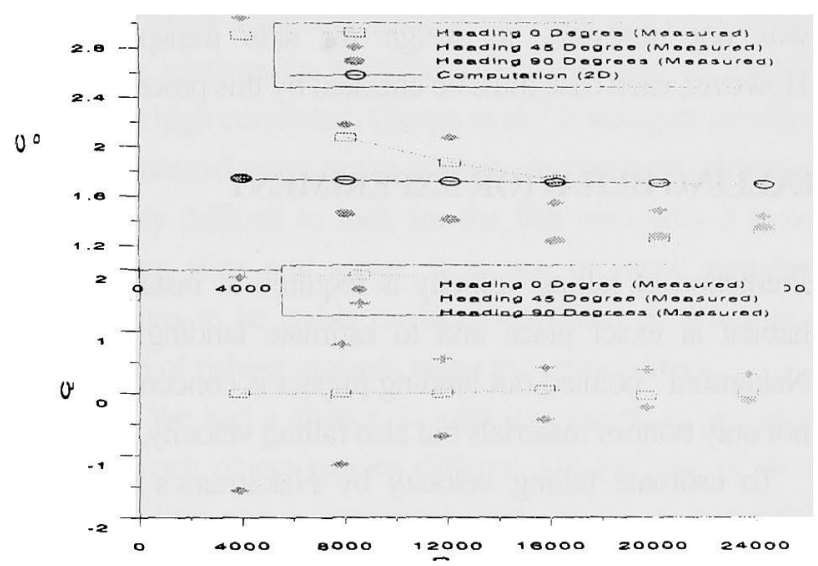

Fig.8 Hydrodynamic coefficients I flow fields.
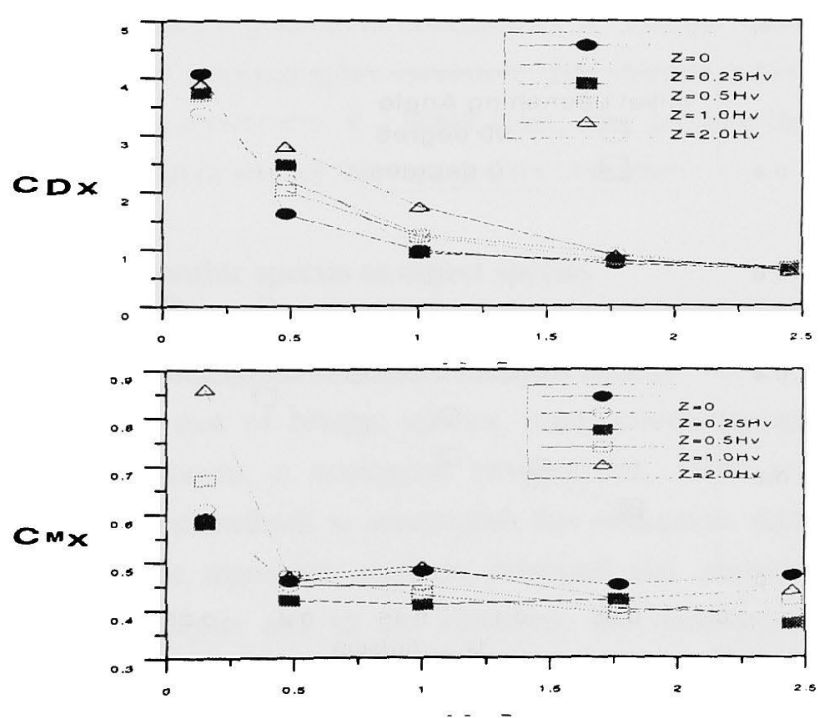

Fig.9 Hydrodynamic coefficients in wave fields. 
estimated as in Fig. 8 from measured force in flow field. Drag coefficient is declined with increase of $\mathrm{Rn}$ from 2,0 to 1.4, though numerical results were about 1.7. Lift coefficients were about 0.3 upward. And drag and inertia coefficients were evaluated from physical experiment in wave field as shown in Fig. 9. Fluid force was measured when sinking vessel habitat was placed at $0,0.25,0.5,1.0$ and 2.0 times of vessel height $(\mathrm{Hv})$.

\section{STABILITY ANALYSIS OF TOWING HABITAT}

After manufacturing old vessel habitat, it must be safely transported to objective site. To avoid capsizing for towing, stability has to be checked in advance. Restoring force is positive when calculated GM is greater than demanded one by CASHIP program of KRISO.

In the case of fishing vessel of 104 ton, which has 0.645 of calculated GM greater than 0.319 of demanded one. It was not necessary to weigh for safe transportation. However, each case must be checked by this procedure.

\section{FALLING BEHAVIOR EXPERIMENT}

Prediction of falling velocity is required to install vessel habitat at exact place and to estimate landing impact. Nakamura ${ }^{7}$ pointed out landing impact is concerned with not only bottom materials but also falling velocity.

To estimate falling velocity by Nakamura's method, vertical drag coefficient is estimated by physical experiment like as Fig. 10. From this study, vertical drag coefficient was about 0.4 .

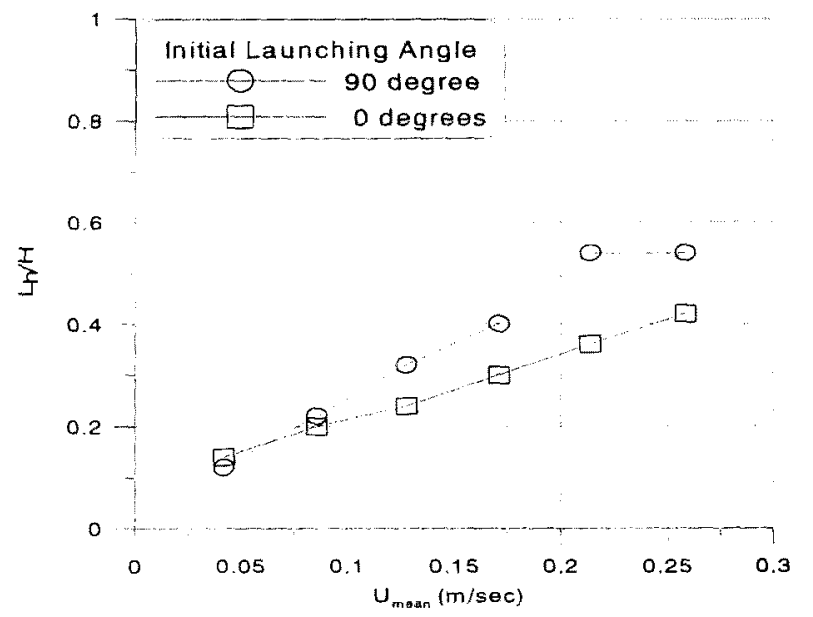

Fig.13 Drift distance for dropping

\section{CONCLUSION}

To create feasible fishing ground using sunken vessel habitat, required techniques of design and arrangement are classified and established based on numerical and physical experiments.

As an index of effective area for the aggregation of fish, reattachment length is about 6 or 7 times of vessel height. To maximize total area by arrayed sunken vessels, distance between each vessel have to be more 4 times of reattachment length.

Hydrodynamic coefficients to calculate fluid forces for analyzing stability are 1.4 to 2.0 of drag coefficient and 2.0 0.4 of lift coefficient in flow field, $1.0-2.0$ of drag coefficient are 0.5 of inertia coefficient.

Procedure of evaluating stability is arranged by CASHIP program. Though some case is not required for ballast, each case must be investigated.

Predicting falling velocity of vessel habitat is essentially required to landing impact and exact placing. Vertical drag coefficient to calculate falling velocity is about 0.4 based on test results.

\section{REFERENCES}

1. Ryu, C.R. Review on marine artificial habitat technology. Proc. Of FOID '92, 1992, 137-154.

2. Kim et al. A study on recycling of old fishing vessel as artificial habitat. MOMAF, 2000; p.76.

3. Kim HJ. et al. Fundamental study for development of multipurpose fisheries structures. Journal of Fishing Port, 1998;

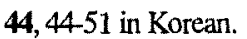

4. Yang C.K and Kim, H.J. A study on the characteristics of flow around s sunken vesel Joumal of Korea Society of Ocean Engineers, 2001; 14(4), 9-16 in Korean with English abstract.

5. Lee Y.H, Choi J.W., Seo M.S. and Saga T. Analysis of uncertainties from PIV input devices. Proc. of VSI-SPIE98 Yokohama, 1998; 232-233.

6. Shoda et al.. Aerodynamics around building exerted to wind. Journal of Japan Architecture:, 1970 in Japanese.

7. Nakamura, M. Suisan doboku gaku. Kogyo Jiji Tsushin-sha, Japan, 1979; 508p.

8. Ryu, C.R. and Kim H.J. A design concept of artificial habitat considering the function of wave wave control and coastal defense. Proc of International Symposium on Coastal Ocean Space Utilization. 